\title{
A Pragmatic Study of Humour in Udurawana's Joke Stories of Sri Lanka: Implications for Second Language Teaching and Learning
}

\author{
Upul Priyantha Gamage \\ Department of Sinhala \& Modern Languages, The Buddhist and Pali University of Sri Lanka, Sri Lanka \\ Wellman Kondowe \\ Mzuzu University, Malawi
}

\begin{abstract}
This paper presents a step by step approach of unpacking humour in joke stories from Udurawana in Sir-Lanka. The analysis has employed two theoretical models: Grice's (1975) theory of Conversational Implicature, and Juckel, Bellman and Varan's (2016) Taxonomy of Humour Techniques. The study has demonstrated that understanding humour involves going through different layers of language given that humour itself does not reside at the surface; but rather inside meanings of words and phrases. The paper appeals to language teachers to utilise humour as a teaching tool owing to the enormous joys it brings in facilitating the teaching and learning of the second language. We conclude that helping learners take baby-steps to decipher humour can lead them into better understanding and fluency of second language learning; an indication of advancement in language acquisition.
\end{abstract}

Index Terms - Udurawana, conversational implicature, humour techniques, second language acquisition

\section{INTRODUCTION}

Humour research has gained much attention in modern studies worldwide with most studies focusing on cartoons and stand-up comedies. The majority of the studies have used linguistic, pragmatic, semantic, psycho-linguistic, and semiotic approaches (Kondowe, Ngwira, \& Madula, 2014; Al-Momani, Badarneh \& Migdadi, 2017; Ali Heidari-Shahreza, 2017; Skalicky, 2018). However, the current study attempts to analyse humour in the joke stories of Udurawana of Sri Lanka by using Paul Grice's (1975) Cooperative Principle; and Juckel, Bellman and Varan's (2016) Humour Techniques Taxonomy as theoretical models. Udurawana is a fabricated name for humour stories in modern folklore of Sri Lanka which have been published informally on different websites and blogs. However, it is rumoured that indeed there lived a real person by the name of Udurawana in the area of Kandy in Sri Lanka although, the fictitious character does not resemble the real person in many aspects. Udurawana's joke stories are famous amongst the educated elites unlike among the illiterates since these stories appear in English. They are rapidly popularised by the young and modern generation. It is noted that in these stories humour is created by playing with language and the interpreter has to calculate the additional implied meaning which can theoretically be called Conversational Implicature or Connotative Meaning in Grice's and Barthe's terms respectively.

\section{A. Rationale}

Studies on humour have been popularised especially with the inception of International Journal of Humour Research that is specifically devoted to publishing research studies on humour. In this paper, humour is not studied in isolation, but rather as having a huge impact on the teaching and learning of second language. However, we understand that the concept of humour in relation to second language teaching and learning is not new. Different research papers have presented interesting findings on the role humour plays in the acquisition of second language (Deneire, 1995; Ali \& Vijay, 2014). However, what is interesting in the present study is the multi-displinary link the paper establishes between humour as a linguistic phenomenon and as a teaching tool. We first analyse humour using Paul Grice's (1975) Cooperative Principle; and Juckel, Bellman and Varan's (2016) Humour Techniques Taxonomy and we apply them into the teaching and learning of second language. We have also noted that there are studies that have used these tools, but studies that have employed both models, and link them to the concept of language teaching and learning, are hard to find.

\section{B. Research Questions}

The study is guided by the following research questions:

i) What humour techniques have been employed in Udurawana joke stories?

ii) How can Grice's Conversational Implicature Theory help unpack humour in these stories?

iii) How can humour facilitate the teaching and learning of the second language? 


\section{Udurawana Joke Stories as Data Texts}

Data for this study comprise of Udurawana joke stories which have randomly been collected from two major blogs and websites. Out of hundreds of stories available in these blogs and websites, we have only selected 10 for a closer analysis on the basis that they contain at least an interaction of more than one character rather than one figure (Udurawana). However, for the purpose of this paper, we have only examined and cited six jokes. Our choice of the stories has been guided by the theory which requires dialogue to determine the extent to which the interactants observe or break the maxims to create implicature (humour).

We have opted for these Udurawana texts as data because we have noted that even though the stories have gained huge popularity in Sri Lanka creating a new chapter of folklore, no serious studies have attempted to investigate how these stories generate humor; hence the reason to undertake this study. Basing on the results from the analysis of Udurawana, the study goes further to discuss the implications of the finding in second language teaching and learning in two parts. Firstly, we have illustrated the significance of humour in language teaching and learning environments. Secondly, using the linguistic analysis of the two models, the paper provides insights on how the teachers can help learners unpack and appreciate humour that appears in the second language in both oral and written forms.

\section{THEORETICAL FRAMEWORKS}

\section{A. The Theory of Conversational Implicature}

The theory of Conversational Implicature (CI) was advocated by Herbert Paul Grice, when he delivered three speeches in his William James lectures at Harvard University in 1967. The theory of "Cooperative Principle" and "Conversational Implicature" came out in his second lecture on "Logic and Conversation" (Wang, 2011). Cooperative Principle (CP) asserts that one should make contributions as is required at the stage at which it occurs, by the accepted purpose or direction of the talk exchange in which one is engaged (Levinson, 2000). CP is illustrated in the following four maxims that both speakers and hearers use as guidelines to interpret the inferences necessary to make sense of the conversation:

i. Maxim of quantity: be informative

ii. Maxim of quality: be truthful

iii. Maxim of relation: be relevant.

iv. Maxim of manner: be perspicuous.

The maxims are unstated assumptions people have when they enter into a conversation. Each participant is expected to adhere to the four maxims. When one of the maxims is exploited or not observed, an alternative meaning is generated (Thomas, 1995; Levinson, 2000). To Grice, this alternative meaning is what is known as Implicature. It is something meant, implied, or suggested as distinct from what is said. The term "implicature" is derived from the word "implicate" which was borrowed from Latin which meant to "intervene, involve, associate, entangle, incriminate" (Wang, 2011). In modern linguistics, implicature describes the implicit meaning or the meaning implied. These are assumptions over and above the meaning of given sentences which the speaker knows, and intends that the hearer will make in the face of an apparently open non-observance of the CP in order to interpret that sentence in accordance with the CP. The CI is generated due to the hearer's ability to calculate the meaning on the basis of (i) the linguistically coded content of the utterance, (ii) the CP and its maxims, (iii) the linguistic and non-linguistic context, (iv) background knowledge, (v) the assumption that both participants are aware of (i)-(iv) (Grice, 1975).To Grice, the calculation follows this pattern:

$\mathrm{B}$ has said that $p$; there is no reason to suppose that $\mathrm{B}$ is not observing the maxim of $\mathrm{CP}$; $\mathrm{B}$ could not be doing this unless B thought that $q$ : B knows that the hearer can see the supposition that he thinks $q$ is required; B has done nothing to stop the hearer thinking that $q$ : B intends the hearer to think that $q$ (Levinson, 2000; Grice, 1975).

According to Grice (1975), an implicature is generated when the participant(s) break or fail to observe the maxims in any of the following five ways: Firstly, a maxim can be flouted and it happens when a speaker fails to observe CP with deliberate intentions of generating an implicature. Secondly, a maxim can be violated when a speaker has an intention to mislead. The maxim can also be infringed which is as a result of imperfect linguistic performance (Levinson, 2000). Fourthly, a maxim can be opted out when a speaker indicates unwillingness to cooperate in the way the maxim requires. Finally, a maxim is suspended when the non-fulfilment of a maxim is expected by participants and, therefore, does not generate any implicature (Levinson, 2000; Kondowe, Ngwira \& Madula, 2014). The fundamental assumption of $\mathrm{CP}$ and $\mathrm{CI}$ is that at some level, the speaker is always observing the $\mathrm{CP}$, even if this is not evident from what is literally said. This means that if the addressee assumes the speaker is following the maxims, but that this is not evident at a literal level, then the addressee infers additional meaning to make up the difference. In other words, the maxims get satisfied if one combines what is literally said and the implicature together.

\section{Humour and Conversational Implicature}

In his Logic and Conversation, Grice has explained how the maxims could be broken which can lead to the production of irony, metaphor, meiosis and hyperbole. Even though Grice has not mentioned how non-observance of the maxims would generate humour, we still find CI to be very relevant to our present study. There is unsaid communication in jokes where funniness resides that leads to the creation of humour. As noted by Tabersky (1998), humour in jokes includes a pragmatic component that utilises implicature as its means. For instance, members of a 
particular society have internalised a set of rules governing their behaviour, both verbal and physical, and humour comes from breaking of both linguistic and social rules. In other words, jokes become successful when they break and violate popular rules which become the centre from which humour emerges; hence the adoption of CI as one of the theoretical backbone is very relevant to the current study.

\section{B. Taxonomy of Humour Techniques}

The theory of Conversation Implicature (CI) discussed above has been employed hand in hand with the tools outlined in Juckel, Bellman and Varan's (2016) Taxonomy of Humour Techniques. In their work, A humor typology to identify humor styles used in sitcoms, Juckel, Bellman and Varan (2016) provide a comprehensive taxonomy of humour techniques that people are likely to employ when creating humour. The following table, therefore, provides the typology as modified by Heidari-Shahreza (2017, p.22) from which tools for analysis have been drawn.

TAXONOMY OF HUMOR TECHNIQUES AS MODIFIED BY HEIDARI-SHAHREZA (2017, P.22)

\begin{tabular}{|c|c|c|}
\hline No. & Humour technique & Short description \\
\hline 1 & Absurdity & Nonsense, a situation that goes against all logical rules \\
\hline 2 & Allusion & Indirect reference \\
\hline 3 & Caught out & Unexpectedly get caught while wrong doing or saying something reprehensible \\
\hline 4 & Clumsiness & Lacking dexterity or grace \\
\hline 5 & Coincidence & A coincidental and unexpected occurrence \\
\hline 6 & Conceptual surprise & Misleading the audience by means of a sudden unexpected change of concept \\
\hline 7 & Condescension & Displaying arrogance by patronising those considered inferior \\
\hline 8 & Deceitful behaviour & Being deliberately misleading, concealing or distorting the truth \\
\hline 9 & Irony & Saying one thing and meaning something else or exactly the opposite of what you're saying \\
\hline 10 & Malicious pleasure & Taking pleasure in other people's misfortune; victim humour \\
\hline 11 & Misunderstanding & Misinterpreting a situation \\
\hline 12 & Outwitting & Outsmarting someone or the establishment \\
\hline 13 & Parody & Imitating a style or a genre of literature or other media \\
\hline 14 & Peculiar face & Making a funny face, grimace \\
\hline 15 & Pun & Playing with the meaning of words \\
\hline 16 & Repartee & Verbal banter, usually in a witty dialogue \\
\hline 17 & Repulsive behaviour & Offensive, aversive, disgusting behaviour \\
\hline 18 & Ridicule & Making a fool of someone, verbally or nonverbally \\
\hline 19 & Rigidity & Someone who thinks along straight lines, who is conservative and inflexible \\
\hline 20 & Self-deprecation & Expressing something negative about oneself \\
\hline 21 & Wit & Ingenious humour \\
\hline
\end{tabular}

The taxonomy provides comprehensive tools that are handy and easy to apply to every linguistic instance. It is easy to pick each technique outlined in the typology, with its provided description, and apply to the text we are working with. However, we have applied this model cautiously after observing that some of the outlined tools can only be applied in a face to face conversation like in stand-up comedies, but not in written texts like the ones under study. Therefore, this model has been very useful in our study in supplementing Grice's CI.

\section{DATA ANALYSIS AND DisCUSSION}

In our analysis of humour in the joke stories under study, we have given prominence to the humour techniques identified in each story. Thus we have taken each tool in the humour taxonomy, and see instances where it applies in the joke stories. Then we have assessed how the audience can find humour in the stories by utilising the CI due to its ability to calculate an argument by providing a step by step illustration. We have first drawn tools from the Juckel, Bellman and Varan (2016) taxonomy then later we have explored the maxim that is broken and the implicature generated which eventually becomes the hilarious aspect. At the end of this paper, we have utilised insights obtained from this section to present their implications in the teaching and learning of second language.

To begin with, our linguistic analysis of Udurawana data using CI, has been guided by the step by step calculation of the model which has been modified:

(1) Udurawana says/asserts that $\boldsymbol{p}$

(2) He believes that $\boldsymbol{p}$ is not observing the maxim of CP

(3) He wants the audience to think of $\boldsymbol{q}$

(4) $\boldsymbol{p}$ implies $\boldsymbol{q}$

Therefore;

(5) Udurawana intends to the audience to see $\boldsymbol{q}$; the humour

We believe that after the identification of humorous aspect is done; following the above steps would be quite helpful to arrive at humour. From the Taxonomy of HumourTechniques, we have identified that puns, misunderstandings, and ridicules are some of the preferred techniques employed in Udurawana joke stories which eventually flout maxim of quality, relation, quantity, and manner.

\section{A. Pun as a Humour Technique}


A pun is broadly defined as a play on words based on their double meanings (Lems, 2013; Juckel, Bellman \& Varan, 2016). Understanding a pun can be very sophisticated, and one needs a good command of language to find humour in a story that has resulted from a pun. Consider the use of a pun by the use of "branch manager" in text 1:

Udurawana gets ready, wears a tie, coat, goes out, climbs a tree, and sits on the branch regularly.

A man: Why do you do this?

Udurawana: I've been promoted to a Branch Manager.

Udurawana responds that he has climbed a tree and sat on a branch because he is now a branch manager following the promotion. The answer is relevant because it has provided us with a missing variable as the question demands, but it is not stating the truth. By definition, a branch manager is an executive who oversees a division, office of a large business or organisation. Therefore, in such a response, readers are aware of three things: Firstly, there is no relationship between climbing up the tree and becoming a branch manager; and secondly, that Udurawana is aware of it. Udurawana has flouted the dictum of quality by stating a blatant lie. However, the lie is not really meant to mislead or cheat someone because he is also aware that readers will not believe and take it seriously. It is a mere pro-social lie with an intention to create humour and just to make the audience laugh it out. The humour becomes successful by playing with the double meanings of the word 'branch'; as part of a tree to which Udurawana is sitting which, he interprets as a subdivision of an office. A branch, therefore, is an example of polysemy which is spelled and pronounced the same but has different meanings (Lems, 2013). Udurawana deliberately lies by exploiting one meaning and applies it into a wrong context which generates a conventional implicature which becomes laughable.

Use of puns has also been identified in text 2 which is in a group of homophones. Homophones are words that sound the same but have different spellings and meanings. In the current text, the plane arrives at Heathrow. Udurawana is excited and anxious to get off. So he goes to the door before anyone and prepares to jump down.

Air hostess: Wait sir, Wait.

Udurawana: $\quad 75$ Kilograms (he jumps off the plane)!

The text generates humour because readers are aware that Udurawana deliberately provided a completely different response to the situation at hand by taking advantage of the homophone 'wait'. He intentionally flouts maxim of relation by providing an irrelevant response to the context at hand which then generates conventional implicature. Therefore, unlike in text 1, which generated implicature on phonemic realisation, humour in text $\mathbf{2}$ is derived based on the phonetic realisation of the word "wait".

\section{B. Humour Caused by Misunderstanding}

Juckel, Bellman, and Varan, (2016) define 'misunderstanding' as a misinterpretation of a situation. Mostly, speaker 'A' utters something to speaker 'B' which the audience understands, but speaker 'B' fails to capture its meaning. In the sample of the texts under study, we have noted a number of instances that Udurawana fails to interpret the verbal statement made by the other participants correctly leading to the wrong action hence humour. In text 3, Udurawana calls the airport customer care line to find out the flying duration from Sri Lanka to Amritsar. The officer who picks the phone does not know the duration and s/he wants to find out from somebody else while keeping Udurawana online:

Text 3:

Udurawana: How long does it take to fly to Amritsar?

Airport officer: $\quad$ just a second.....

Udurawana: Thank you! (He cuts the line).

In text 3 , the airport officer is cooperative and polite by responding just a second, a simple telephone etiquette. Udurawana misunderstands the response and takes it literally. This eventually leads to humour as the audience is fully aware that a plane cannot fly for 'a second'. Udurawana derives the literal meaning of this utterance which does not make sense in the current context. However, it can be argued that Udurawana is justified in his action since the officer's response flouts maxim of quantity. It does not tell Udurawana to 'wait for a moment' while the officer consults. To someone who is not well versed with telephones etiquette like Udurawana, the officer's response is not adequately informative. CP calls that in any conversation, we must make sure that our contributions are as informative as is required for the current purpose of the exchange. If the airport officer had provided some more information, there could be no room to generate such humour.

Similarly, a case of misunderstanding has also resulted into humour in text 4. In the story, the house owner is delighted with the way Udurawana has done all the paint work on his house, and he gladly gives him a bonus pay and advises him to take his wife for a dinner.

Text 4:

House owner: $\quad$ You did a great job (he said as he gives Udurawana his pay). So in order to thank you, here's an extra 500 bucks to take the wife out to dinner and a movie.

Udurawana: $\quad$ No! I can't accept that (he declined)

House owner: $\quad$ I insist. It would make me very happy if you do it.

Udurawana: Well! (reluctantly) if you really don't mind it, I'll do it.

(Later during the night, the doorbell rings and it is Udurawana, standing there holding a bouquet of flowers).

House owner: What's the matter, did you leave something behind? 
Udurawana: $\quad$ Nope! I'm just here to take the wife out to dinner and a movie like you asked.

The conversation in text four is informative, but not as is required due to the missing variable- the possessive determiner 'your'. Udurawana misinterprets the wife ('your wife') and thinks it means the house owner's wife. This lack of understanding between the two breeds a particularised conversational implicature which creates humour. The statement 'to take the wife out to dinner and a movie' flouts the maxim of manner by being vague and ambiguous which eventually has led to the misunderstanding. However, it can further be argued that Udurawana is not being truthful, and deliberately neglects to read the statement with context relativism. Unless otherwise, but the audience is aware that in an ideal situation, a boss cannot send his wife to go out for dinner and movie with his worker, therefore Udurawana's misinterpretation of the same becomes hilarious.

In text 5 , Udurawana got the $4^{\text {th }}$ child. He fills data in the birth certificate:

Text 5:

Mother: $\quad$ Sri Lankan

Father: $\quad$ Sri Lankan

Baby: Chinese

Officer: How come you write "Chinese" when both parents are Sri Lankans?

Udurawana: Ahhh... I read in the newspaper, 'every $4^{\text {th }}$ person born on the Earth now is a Chinese'.

This is another analogy made by Udurawana based on a wrong presupposition. The news report uses hyperbole to highlight the world's highest population of China. To say "every $4^{\text {th }}$ person born on the Earth now is a Chinese" does not entail that whoever is born $4^{\text {th }}$ anywhere in the world, be it in a family, is Chinese. Udurawana misinterprets the statement and applies it literally which brings up the funny aspect. Due to this misunderstanding, Udurawana flouts the maxim of relevance due to his misapplication of information.

\section{Ridicule as a Humour Technique}

Ridicule, as a humour technique, is defined as making fool of someone, verbally or nonverbally so much so that in the end, it makes the audience laugh (Juckel, Bellman \& Varan, 2016). In text 6, Udurawana goes to a shop where TVs are sold and manages to incite humour by making fun of the shop owner.

\section{Text 6:}

Udurawana: Do you have colour TVs?

Shop owner: $\quad$ Sure

Udurawana: $\quad$ Give me a green one, please.

Udurawana wants to fool the shop attendant by bringing in a controversial perspective to the meaning of colour in the context of TV which is different from the ordinary meaning we all know. The shop owner and the audience have a presupposition that the customer knows the meaning of 'colour TVs' as it is commonly shared by everyone. So, the answer provided by the shop owner is relevant to the question raised by Udurawana. It can be said therefore that Udurawana is also correct in asking for a green TV because the topic at hand is about colour TVs, and he is asking for a green one which is just fine. The two are trading on the same topic. However, the shop attendant and the readers know that Udurawana is not sincere in asking for a green colour TV. Even though it is possible to have a red, black, or silver $\mathrm{TV}$ at the outer side, Uduruwana is just being radical by asking for a green one. He deliberately breaks the maxim of quality in order to make fun out of the shop attendant by generating particularised implicature.

\section{Implications of Humour in Second Language Teaching and Learning}

From the above analysis, the paper now seeks to illustrate the need for language teachers to employ humour as a teaching tool in second language classrooms, and how learners can be equipped with skills of understanding and appreciating the humour in spoken or written discourses. Despite the wide range of pro-social functions inherent in humour for the second language classroom, it is saddening though to note that some teachers and language educators consider humorous language as inappropriate and meaningless for the language classroom. Consequently, humour becomes rarely used in lesson plans or lesson units as most teachers stick to lesson objectives and syllabus coverage. This paper agrees with research and teaching experiences that have shown a positive correlation between humour and effective teaching. When employed ingeniously, humour remains part and parcel of effective teaching, and its role in facilitating the learning and acquisition of the second language cannot be overemphasised. As similarly noted by Azizinezhad and Hashemi (2011), humour helps in keeping students interested, motivated and get hold of their attention. It can improve classroom atmosphere, increase enjoyment and facilitate student-teacher interactions. A teacher that employs humour as part of his teaching culture is likely to defuse tension and anxiety amongst students. S/he is also more likely to bond, ease relationships and elicit cooperation with his/ her learners. In short, humour in the second language classroom offers enormous opportunities for learning. Moreover, learners ability to decipher humour can lead to a deeper understanding that is necessary for true fluency in second language learning (Lems, 2013). However, humour as a teaching tool must be employed cautiously because there is a danger of the teacher drifting away from the lesson objectives and turn the class into play stage and fun time (Chiyembekezo, Kondowe, \& Ngwira, 2019).

However, the process of unpacking humour in jokes requires the highest fluency from the learners especially when the jokes appear in the second language as the case with Udurawana. The majority of Sri-Lankans second language learners with low ability proficiency levels may not be able to decipher the humour owing to its nature that the humour 
is buried inside word meanings. It must further be stated that understanding the humour in jokes is part of the language acquisition process, and it does display one's advanced levels of second language mastery and acquisition; hence, it must not be ignored in any second language classroom. This way, learners can also learn to appreciate the beauty of the language as used in real life situations and possibly develop skills of creating humour on their own.

The discussion above has observed that prolific language users employ different linguistic techniques for creating humour by deliberately using puns, misunderstandings, or ridicule among others in face to face interactions. We also established that use of humour might be problematic especially in such environments where the learners have low proficiency levels of the language being used. Therefore, few steps need to be taught in order for learners to fully grapple with the humour and the language at large. Firstly, learners must start by unpacking the wide variety of meanings for words or phrases including possible meanings of such words or phrases. In the case of puns, for instance, learners must be taught for instance; homophones, homonyms, synonyms and antonyms. They must have access to all their possible meanings and be able to identify them. As noted by Lems (2013), if there is a close sounding pun, students must be able to figure out what the other word sounds like as the case with 'wait' and 'weight' in text 2. Finally, they need to consolidate the two possible meanings of the word, phrases, and sentences and be able to compare them in the context of use. When all of those steps are exhausted, there is an instance where the two meanings smoothly map into each other, and that is the time to laugh (refer to text 1 and 2). Unpacking these steps enhances our appreciation of the complexity required to understand an English pun, a privilege which is often enjoyed by those with advanced language proficiency (Lems, 2013).

Similarly, learners must be made to understand that language has a varied number of tools available at their disposal that can attract and delight their audience. As such, when a teacher brings in the concept that the majority of words in a language have multiple meanings, it is important to show the learners how the difference in meanings can lead to confusions, contradictions, and misunderstandings; and the teacher must point out that some of the confusions and misunderstandings can be quite funny just as in text 3, 4, and 5 above. Hence, individuals with a high sense of humour will capitalise on that versatility of words to induce laughter and free classroom atmosphere. The misunderstandings can be intended or non-intended but the end result is the beauty that comes out with it which enhances the learning and acquisition of a second language. The discussion, therefore, highlights how formal linguistic features, as well as the pragmatic components of $\mathrm{CP}$ and $\mathrm{CI}$, can lead to the enjoyment of humour as a pedagogical tool in creating a conducive learning environment necessary for second language learning.

\section{CONCLUSION}

This paper has provided a step by step approach of unpacking humour in joke stories by using Udurawana data of Sir Lanka. The analysis has employed Grice's (1975) theory of Conversational Implicature and Juckel, Bellman and Varan's (2016) Taxonomy of Humour Techniques as theoretical models. The study has discovered that understanding of humour involves going through different layers of language as most of the humour does not reside at the surface; but rather deep inside the meanings of words and phrases. We have discovered that Udurawana's jokes create humour by using puns, misunderstandings, and ridicules as its major techniques which in the end flouts almost all the maxims in Grice's Cooperative Principle. It has been noted that the audience does not take the flouting of the maxims by the interactants as failure to understand one another, but rather deliberate and intentional techniques to make them laugh. However, for someone to understand and appreciate the beauty of humour that appears in a second language like that of Udurawana, the study has provided some insights on the need for language teachers to employ humour as a language teaching tool which can help captivate the learners, motivate them and get them glued to the lesson. Humour can further improve the classroom atmosphere, increase freedom and facilitate student-teacher interaction. Therefore, language teachers must take deliberate steps in training second language students take baby-steps for them to appreciate humour starting from the basic meanings of words to how the words build on each other so that humourous discourse can become wholesome. Second language learners' success in unpacking humour will be one of the indications of advances in second language acquisition.

\section{REFERENCES}

[1] Ali, Z. and Vijay, K (2014). The role of verbal humor in second language education. International Journal of Research Studies in Education 3(2): 3-13.

[2] Al-Momani, K, Badarneh, M. A., and FathiMigdadi, F. (2017). A semiotic analysis of political cartoons in Jordan in light of the Arab Spring. Humour 30 (1): 63-95.

[3] Azizinezhad, M. and Hashemi, M. (2011). Humour: A Pedagogical Tool for Language Learners. Procedia-Social and Behavioural Sciences, 30: 2093-2098.

[4] Binsted, K., Bergen. B., and Mckay, J. (2014). Pun and Non-Pun Humor in Second Language Learning. Available at: https://www.researchgate.net/publication/228529665_Pun_and_Non-Pun_Humor_in_Second-Language_Learning (retrieved on 2nd March, 2019.

[5] Chiyembekezo, R., Kondowe, W., and Ngwira, F.F. (2019). Teaching English Speaking Skills to L2 Students using Role -Play Method: What do Teachers in Malawi Say? Researchers World-Journal of Arts, Science \& Commerce, X(1): 12-20.

[6] Deneire, M. (1995). Humour and Foreign Language Teaching. International Journal of Humour Research, 8(3): $285-298$.

[7] Gan, X. (2015). A Study of the Humour Aspect of English Puns: Views from the Relevance Theory. Theory and Practice in 
Language Studies 5(6): 1211-1215.

[8] Grice, H. (1975). Logic and Conversation. Harvard: Harvard University Press.

[9] Heidari-Shahreza, M. A. (2017). A rhetorical analysis of humour styles and techniques used in Persian stand-upcomedy. Humor: 30(4), 359-381.

[10] Juckel, J., Bellman, S. and Varan, D. (2016). A humor typology to identify humor styles used in sitcoms. Humor 29(4).583-603.

[11] Kondowe, W., Ngwira, F.F., and Madula, P. (2014). Linguistic Analysis of Malawi Political Newspaper Cartoons on President Joyce Banda: Towards Grice's Conversational Implicature. International Journal of Humanities and Social Science, 4(7): 40-51.

[12] Lems, K. (2013). Laughing All the Way: Teaching English Using Puns. English Teaching Forum, 1: 26-33.

[13] Levinson, S.C. (2000). Pragmatics. Cambridge: Cambridge University Press.

[14] Taberski, D., J. (1998). A Grice Analysis of a Situation Comedy. Theses Digitization Project 1439.

[15] Sinhara Jokes. (2008, November). Available on http://vihilulanka.blogspot.com/2008/12/udurawana-jokes.html (Accessed on 14th March, 2019).

[16] Skalicky, S. (2018). Lexical priming in humorous satirical newspaper headlines. Humour, 0(0): 1-20.

[17] Sri Lankan Jokes. (2008, July). Available on: https://jokeslanka.blogspot.com/2008/07/udurawana-jokes-collection.html (Accessed on 15 March, 2009).

[18] Thomas, J. (1995). Meaning in Interaction: An Introduction to Pragmatics. Beijing: Foreign Language Teaching and Research Press.

[19] Wang, H. (2011). Conversational Implicature in English Listening Comprehension. Journal of Language Teaching and Research, 2 (5): 1162-1167.

Upul Priyantha Gamage is a Lecturer in Linguistics \& Literature at the Faculty of Language Studies, Buddhist and Pali University of Sri Lanka. He graduated from the University of Colombo and earned his Master degree in General Linguistics from the University of Kelaniya, Sri Lanka in 2010. His first PhD was in Sociolinguistics with special reference to language contact phenomenon, and now he is reading for the second $\mathrm{PhD}$ in the same discipline with special reference to Language Policy at Central China Normal University. He has published six books and several research papers in Applied Linguistics, Sociolinguistics and Literature.

Wellman Kondowe is a Senior Lecturer in Applied Linguistics at Mzuzu University, Malawi. He obtained his Masters Degree in Applied Linguistics in 2014 at Central China Normal University, and he is currently pursuing doctorate studies at the same in stitution. He has published different research papers on Applied Linguistics, Language and Law, Political Discourse, Health Communication, and Education. 